\title{
Response to R-CHOP in HPV-related squamous cell carcinoma of base of tongue: a case report
}

\author{
Ting Martin Ma', Hyunseok Kang ${ }^{2}$, Steven P. Rowe ${ }^{3}$ and Ana P. Kiess ${ }^{1 *}$
}

\begin{abstract}
Background: Synchronous squamous cell carcinoma of the head and neck (HNSCC) and non-Hodgkin's lymphoma is a rare clinical scenario. It is unknown whether the R-CHOP chemotherapy for lymphoma would also be active against HNSCC. Herein, we present such a case and a review of the literature.

Case presentation: A 64 year-old female presented with painless jaundice. CT demonstrated a retroperitoneal mass and pathology showed follicular lymphoma. A base-of-tongue $\mathrm{HPV}^{+}$squamous cell carcinoma was found incidentally on staging CT. R-CHOP chemotherapy was initiated. After 3 cycles of R-CHOP the lymphoma had a complete metabolic response and, unexpectedly, the HNSCC also demonstrated excellent response. The patient received another 3 cycles followed by radiation to the HNSCC and to date is in remission for both cancers.
\end{abstract}

Conclusions: This case highlights the exquisite sensitivity of HPV-related HNSCC, which should be taken into consideration in treatment prioritization of a concurrent diagnosis of a second cancer.

Keywords: Squamous cell carcinoma, Non-Hodgkin's lymphoma, R-CHOP, Synchronous, HPV

\section{Background}

Squamous cell carcinoma (SCC) accounts for more than $90 \%$ of tumors in the head and neck [1]. For patients with head and neck squamous cell carcinoma (HNSCC), a synchronous second primary cancer (SPC) has been reported in $1-5 \%$ of cases $[2,3]$. Typically SPCs are also SCCs. An $\mathrm{SPC}$ of lymphogenic origin is extremely rare. In one study, $3.5 \%$ of the SPCs were non-Hodgkin lymphoma (NHL) with a majority of the index primaries seen in the oropharynx (39.2\%) [3]. With the emergence of human papillomavirus (HPV) as a distinct risk factor for oropharyngeal HNSCC, the risk of SPC carried by oropharyngeal cancers has decreased [2]. On the other hand, there is a growing body of evidence demonstrating that patients with NHL or chronic lymphoid leukemia are immunosuppressed, partially attributed to disease biology itself, and are more susceptible to other malignancies including cutaneous SCC [4-10]. Various mechanisms of immune escape in NHL have been described, including impaired HLA-

\footnotetext{
* Correspondence: akiess1@jhmi.edu

'Department of Radiation Oncology and Molecular Radiation Sciences, The Johns Hopkins University School of Medicine, Baltimore, MD 21231, USA Full list of author information is available at the end of the article
}

mediated cancer cell recognition [11], deranged apoptotic mechanisms, and changes in the tumor microenvironment involving regulatory $\mathrm{T}$ cells and tumor-associated macrophages [12-15].

Here, we report a unique case of synchronous follicular lymphoma and $\mathrm{HPV}^{+}$squamous cell carcinoma at base of tongue in which the SCC demonstrated an excellent response after only 3 cycles of R-CHOP chemotherapy. We also review the literature and cite other cases of synchronous SCC of aerodigestive tract and lymphoma treated with upfront R-CHOP chemotherapy, with a discussion of possible mechanisms of how component(s) of $\mathrm{R}-\mathrm{CHOP}$ chemotherapy led to the regression of SCC.

\section{Case presentation}

A 64 year-old Caucasian female former smoker (4 packyear) originally presented to the emergency department with painless jaundice. Physical exam revealed an afebrile female with scleral icterus and jaundice. Her abdomen was soft, non-tender, and non-distended in all quadrants with normal bowel sounds and no organomegaly. CT imaging demonstrated a large $(10 \mathrm{~cm})$ retroperitoneal mass, necessitating biliary stenting. Fine needle aspiration of the mass 
revealed a $\mathrm{CD}_{10}{ }^{+}$clonal $\mathrm{B}$ cell population by flow cytometry, consistent with presumptive B cell lymphoma. During the staging workup for the lymphoma, right-sided cervical level IIA and III lymphadenopathy was found incidentally during a routine dental check-up, which was initially thought to be of the same disease process. She had no supraclavicular or axillary lymphadenopathy. CT demonstrated right level II/III LN and possible right base of tongue (BOT) mass. Flexible laryngoscopy revealed an exophytic mass involving the right BOT that extended to the right glosso-tonsillar sulcus and beyond the midline measuring approximately $3 \mathrm{~cm}$ (Fig. 1). Excisional biopsy of two right cervical lymph nodes unexpectedly demonstrated squamous cell cancer (SCC) that was positive for p16 and HPV. Subsequently, positron emission tomography/computed tomography (PET/CT) demonstrated an FDG-avid right BOT mass $(2.3 \times 0.9 \mathrm{~cm})$ with right-sided level IIA, IIB and III lymphadenopathy (all $<3 \mathrm{~cm}$ ), consistent with biopsy-proven HPV-associated SCC (Fig. 2). There was also an intensely FDG-avid retroperitoneal mass $(8.2 \times 13.4 \times 10$. $7 \mathrm{~cm}$ ) along with left mesenteric, left periaortic, and left retroperitoneal lymph nodes (Fig. 3). Laparoscopic biopsy of gastroepiploic, mesenteric, and gastrocolic lymph nodes confirmed follicular lymphoma. Pathology showed relatively low number of centroblasts (fewer than 15 per high power field) compatible with low grade follicular lymphoma (WHO grade 1-2) with significantly elevated Ki-67 proliferation index $(\sim 80 \%)$ suggesting clinical behavior similar to WHO grade 3 follicular lymphoma. Omentum and liver were not involved. Therefore, a diagnosis of synchronous stage IV T2N2bM0 $\mathrm{HPV}^{+} \mathrm{SCC}$ of right BOT and stage IIAX follicular lymphoma was made. At the time, she was relatively asymptomatic from the BOT cancer. She denied dysphagia, odynophagia, trismus, otalgia, or speech or voice change. She also denied night sweats, fevers, significant weight loss, or infectious symptoms. Videofluoroscopic swallow study evaluation was normal. ECOG performance status was 1. After stenting, the patient's bilirubin normalized and she was asymptomatic. Her case was discussed at multidisciplinary case conferences, and the initial plan was to treat the BOT cancer first due to its likely curability and shorter treatment course.

One month later, however, the patient was admitted to the hospital because of worsening abdominal pain. Given concern for lymphoma becoming increasingly symptomatic, R-CHOP (rituximab, cyclophosphamide, doxorubicin, vincristine, and prednisone) chemotherapy was initiated. She tolerated therapy well and had resolution of abdominal pain. After completion of 3 cycles of R-CHOP, PET/ CT scan demonstrated interval markedly decreased size and uptake of the retroperitoneal mass, as well as interval resolution of the FDG-avid BOT lesion, and most of the FDG-avid cervical lymph nodes (Figs. 2 and 3). She had no symptoms referable to lymphoma at this time. Nasopharyngolaryngoscopy also revealed no residual fullness in the area of the right BOT (Fig. 1). After completion of another 3 cycles of R-CHOP (in total 6 cycles), PET/CT scan demonstrated sustained metabolic resolution of the abdominal mass. However, FDG-avid right BOT lesion as well as right cervical level II and III nodes had become slightly more prominent compared to the end of cycle 3 . The decision was made to start 7-week concurrent chemoradiation with weekly cisplatin $40 \mathrm{mg} / \mathrm{m}^{2}$ for the SCC. Unfortunately, she was found to be neutropenic and cisplatin was switched to cetuximab. At the end of the first cetuximab infusion, she developed a Grade 3 infusion reaction with rigors and chest pain and was diagnosed with NSTEMI. An attempt to re-initiate cisplatin treatment after ANC normalized was unsuccessful as patient experienced fever and altered mental status necessitating hospital admission. She had received a total of one dose of cetuximab and two doses of cisplatin before the decision was made to proceed with radiation therapy (RT) without further chemotherapy. In total, the patient received 6996 cGy, 212 cGy per day in 33 fractions with coverage of the oropharynx and bilateral neck using tomotherapybased image-guided intensity-modulated radiation therapy. Despite experiencing significant anterior mouth sores from cetuximab early in treatment, as well as significant oropharynx mucositis late in treatment, she was ultimately
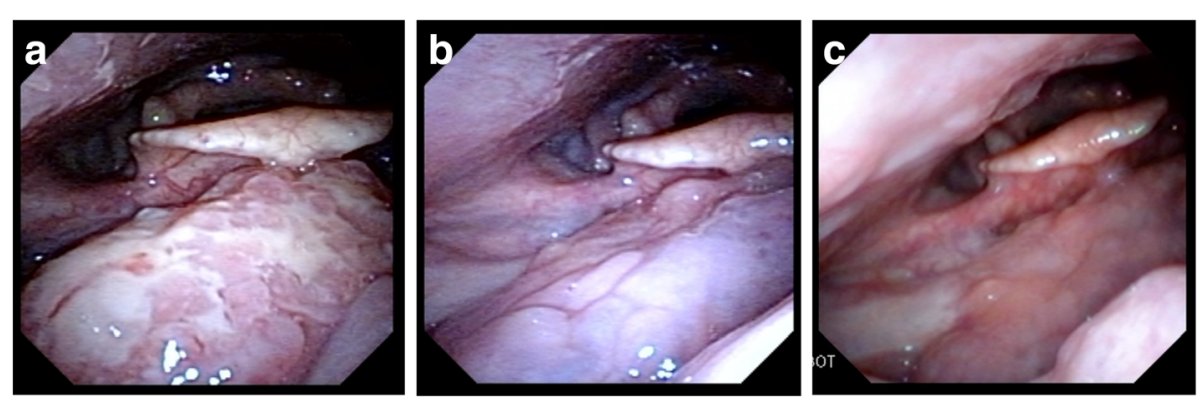

Fig. 1 Flexible nasopharyngolaryngoscopy view of the right BOT mass before treatment (a), after 3 cycles of R-CHOP chemotherapy (b) and after the completion of 6 cycles of R-CHOP chemotherapy (c) 


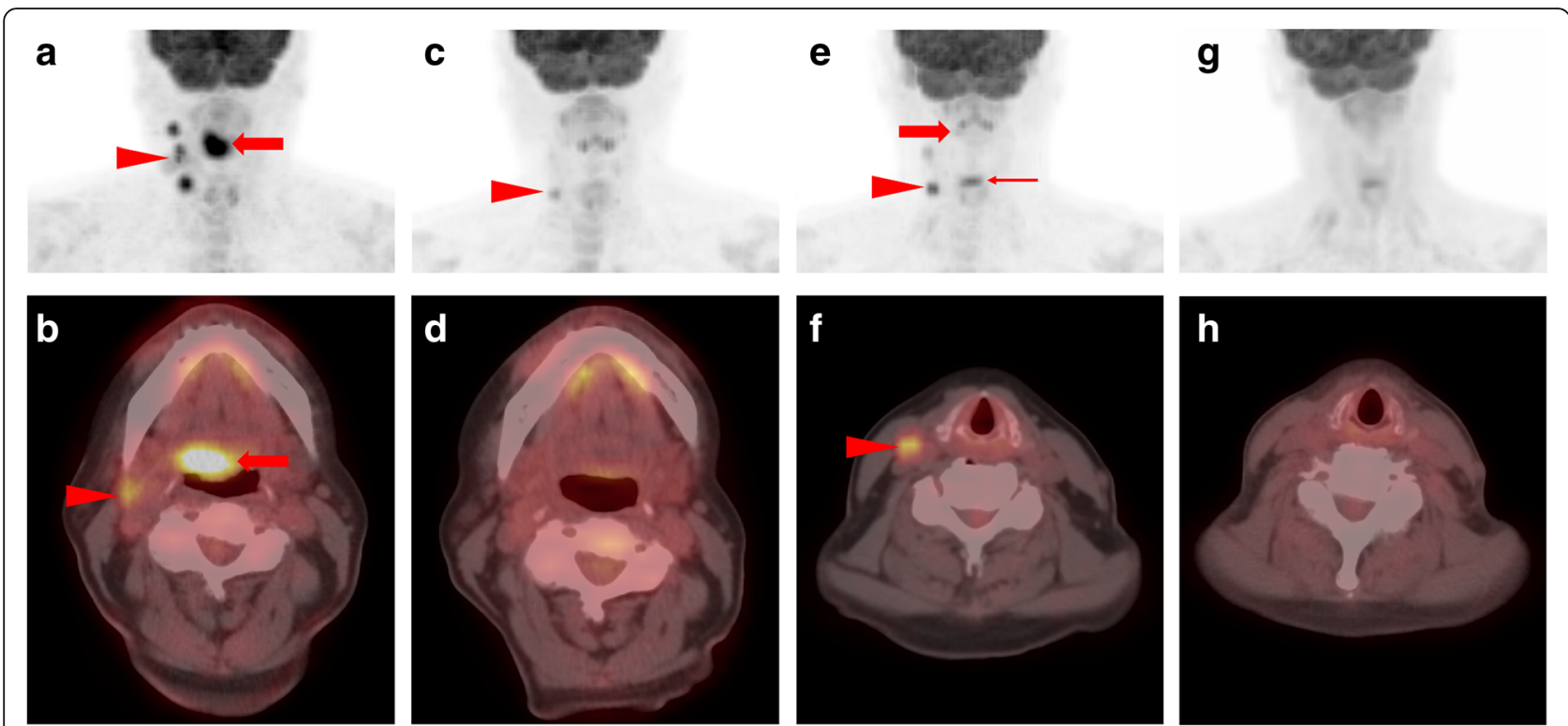

Fig. 2 a Baseline head and neck maximum intensity projection (MIP) image demonstrating focal FDG uptake in the patient's BOT HNSCC (red arrow) as well as ipsilateral cervical adenopathy (red arrowhead). b Representative axial PET/CT slice from the same time point as in (a) which delineates the BOT HNSCC (red arrow) and also highlights one of the right-sided cervical lymph nodes (red arrowhead). c Head and neck MIP image following 3 cycles of R-CHOP demonstrates complete metabolic response in the patient's BOT HNSCC and partial response in the ipsilateral cervical adenopathy (red arrowhead). $\mathbf{d}$ Axial PET/CT image from the same time point as (c) shows no abnormal uptake at the BOT (persistently FDG-avid cervical nodes are not shown on this slice). e Head and neck MIP image following completion of R-CHOP therapy demonstrates very subtle increased uptake in the BOT HNSCC (red arrow, barely visible) and increasing uptake in ipsilateral cervical lymph nodes (red arrowhead). Note normal physiologic activity in the vocal cords (thin red arrow). $\mathbf{f}$ Representative axial PET/CT image through the neck shows an FDG-avid right level III lymph node compatible with residual HNSCC. $\mathbf{g}$ Head and neck MIP and (h) axial PET/CT images following completion of chemoradiation therapy show no evidence of metabolically active primary or nodal HNSCC

able to complete RT without an enteral feeding tube. At 3-month follow-up, she had no clinical or radiographic evidence of disease on exam or PET/CT scan. At the time of this manuscript submission, 3 years after completion of the radiation therapy, she remained in remission for both cancers.

\section{Discussion}

SCC is the most common malignant tumor of the head and neck and may arise in the oral cavity, pharynx, larynx, or sinonasal cavities. Although most HNSCCs are related to alcohol and/or tobacco use, the incidence of HPV-associated HNSCC is on the rise worldwide [16]. In the United States, more than half of cancers diagnosed in the oropharynx are linked to HPV type 16 [17]. Interestingly, one Danish study demonstrated that HPV infection is associated with an increased incidence of both Hodgkin and NHL using conization as a surrogate marker [18]. Therefore it is plausible that in this case, chronic immune activation induced by persistent HPV infection and the failure of the immune system to clear HPV infection and to control lymphoma development could have contributed to lymphomagenesis in addition to its role in the pathogenesis of HNSCC.

$\mathrm{HPV}^{+} \mathrm{OPC}$ is a distinct type of $\mathrm{OPC}$ and has very different biology compared to its $\mathrm{HPV}^{-}$counterparts.
Patients with HPV-related OPCs have a more favorable prognosis, in part due to the natural biology of the cancer and in part because these tumors are more responsive to chemotherapy and radiotherapy than $\mathrm{HPV}^{-}$cancers $[19$, 20]. Definitive treatment of locoregionally advanced (III/IV) OPC often requires a multimodality approach that may include chemotherapy, RT, concurrent chemoradiation (CRT) and/or surgery. Cisplatin is considered the gold standard for CRT, with cetuximab as an alternative agent [21]. Other common chemotherapy agents including paclitaxel, docetaxel, 5-FU, hydroxyurea and carboplatin have also been used in treating OPC.

An unexpected observation in this case was the excellent response of BOT HNSCC to R-CHOP chemotherapy intended for follicular lymphoma, even after only 3 cycles. Despite slight regrowth seen at the end of cycle 6 , the SCC responded very well to the initial 3 cycles of $\mathrm{R}$-CHOP, judged by the interval resolution of the FDGavid BOT lesion and most of the FDG-avid cervical lymph nodes and negative nasopharyngolaryngoscopy results. The patient was also free of symptoms from SCC. The observed effect of R-CHOP on $\mathrm{HPV}^{+}$head and neck cancer was unexpected because components of this regimen do not overlap with any routine chemotherapy regimen for HNSCC. A literature search 

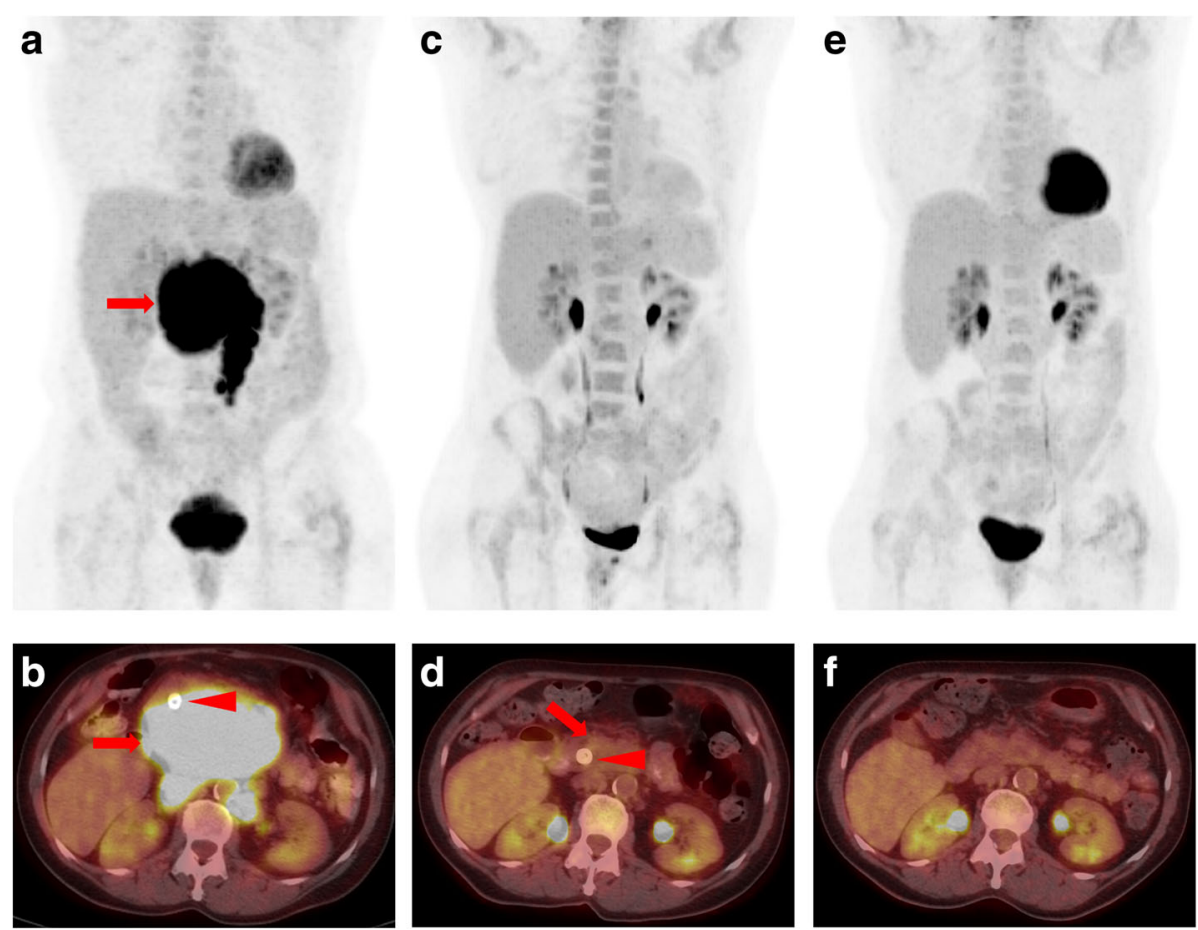

Fig. 3 a Baseline whole-body MIP image demonstrating intense FDG uptake in a large retroperitoneal mass (red arrow) compatible with patient's follicular lymphoma. b Representative axial PET/CT image from the same time point as in (a) showing the large, FDG-avid mass (red arrow). Note the common bile duct stent (red arrowhead) that is markedly anteriorly displaced by the lymphomatous mass and explains the patient's presentation with obstructive jaundice. $\mathbf{c}$ Whole-body MIP image following three cycles of R-CHOP shows no residual metabolically active lymphoma. $\mathbf{d}$ Representative axial PET/CT image from the same time point as in (c) is notable for the presence of minimal residual abnormal soft tissue in the retroperitoneum (red arrow, Lugano 2), with uptake equal to blood pool, compatible with a complete metabolic response. The common bile duct stent is in near-orthotopic location now that the retroperitoneal mass has dramatically reduced in size (red arrowhead). e Whole-body MIP image at the end of therapy, again demonstrating no metabolically active tumor. f Representative axial PET/CT image from the same time point as in (e) again depicts the complete metabolic response (Lugano 1) and also the removal of the common bile duct stent

revealed 3 case reports of synchronous SCC of aerodigestive tract and lymphoma treated with upfront R-CHOP chemotherapy (Table 1). Lymphoma achieved complete response in 2 cases $[22,23]$ and partial response in the other [24]. In contrast, SCC achieved partial response in 1 case [22] and stability/progression in 2 cases $[23,24]$. Of note, none of these cases were HPVrelated SCC.
Among the components of R-CHOP, only 2 agents have been evaluated as single chemotherapy agents in HNSCC. Cyclophosphamide had a response rate of $36 \%$ in 77 patients in one study [25] and doxorubicin had a response rate of $24 \%$ in another study [25]. Vinblastine, a closely related agent to vincristine, demonstrated a response rate of 29\% [25]. However, these early studies should be interpreted with caution due to lower

Table 1 Case reports of synchronous SCC of aerodigestive tract and lymphoma treated with upfront R-CHOP chemotherapy

\begin{tabular}{|c|c|c|c|c|c|c|}
\hline Study & $\begin{array}{l}\text { Patient } \\
\text { characteristics }\end{array}$ & $\begin{array}{l}\text { Index } \\
\text { primary }\end{array}$ & $\begin{array}{l}\text { Synchronous } \\
\text { secondary } \\
\text { primary }\end{array}$ & $\begin{array}{l}\text { Treatment } \\
\text { regimen }\end{array}$ & Response & Remarks \\
\hline $\begin{array}{l}\text { Morita et al., } \\
2009 \text { [22] }\end{array}$ & $\begin{array}{l}\text { 75-year-old } \\
\text { female }\end{array}$ & $\begin{array}{l}\mathrm{DLBCL} \\
\text { (lower lip) }\end{array}$ & $\begin{array}{l}\text { SCC (buccal } \\
\text { mucosa) }\end{array}$ & $\begin{array}{l}6 \text { cycles of } \\
\text { R-THP-COP }\end{array}$ & $\begin{array}{l}\text { Complete response for DLBCL, } \\
\text { partial response for SCC }\end{array}$ & $\begin{array}{l}\text { SCC was subsequently treated with } \\
\text { tegafur, gimeracil and oteracil } \\
\text { potassium with partial response }\end{array}$ \\
\hline $\begin{array}{l}\text { Oikonomou } \\
\text { et al., } 2013 \\
\text { [24] }\end{array}$ & $\begin{array}{l}\text { 72-year-old } \\
\text { male, } 20 \text { pack- } \\
\text { yr smoking hx }\end{array}$ & $\begin{array}{l}\text { BALT } \\
\text { Lymphoma } \\
\text { (LLL) }\end{array}$ & $\begin{array}{l}\text { low-differentiated } \\
\text { lung SCC (RML) }\end{array}$ & $\begin{array}{l}3 \text { cycles of } \\
\text { R-CHOP }\end{array}$ & $\begin{array}{l}\text { Significant reduction in size of } \\
\text { lymphoma and stability of the } \\
\text { lung SCC }\end{array}$ & $\begin{array}{l}\text { 9-month follow-up CT revealed pro- } \\
\text { gression of the lung cancer with dis- } \\
\text { tant metastatic disease }\end{array}$ \\
\hline $\begin{array}{l}\text { Fujii et al., } \\
2014 \text { [23] }\end{array}$ & $\begin{array}{l}\text { 68-year-old } \\
\text { female }\end{array}$ & $\begin{array}{l}\text { DLBCL (Left } \\
\text { cervical } \\
\text { LNs) }\end{array}$ & $\begin{array}{l}\text { Lung SCC (RUL } \\
\text { and hilar and } \\
\text { mediastinal LNs) }\end{array}$ & $\begin{array}{l}3 \text { cycles of } \\
\text { R-CHOP }\end{array}$ & $\begin{array}{l}\text { Complete response for DLBCL; } \\
\text { pulmonary SCC and right hilar } \\
\text { LN stable/increased }\end{array}$ & $\begin{array}{l}\text { Radical surgery performed after } \\
3 \text { cycles of R-CHOP to resect lung } \\
\text { SCC }\end{array}$ \\
\hline
\end{tabular}

DLBCL diffuse large B-cell lymphoma, SCC squamous cell carcinoma, BALT bronchial-associated lymphoid tissue, LLL left lower lobe, RML right middle lobe, RUL right upper lobe, $L N$ lymph node, $R$-THP-COP rituximab, pirarubicin, cyclophosphamide, vincristine, and prednisolone 
prevalence of HPV-related SCC during the study period [16], limited size, and a lack of information concerning prior treatment and nutritional and performance status.

Historically, these agents have also been evaluated as combination therapies with other chemotherapy agents, mostly in the 1980's and 1990's. Many cyclophosphamide combinations have been reported, as this is an agent with very broad activity in a variety of epithelial tumors. The most common combination utilized was with bleomycin, methotrexate, and 5-FU. The overall response rate was $47 \%(132 / 279)$ with a range of $11-69 \%$ [26].

Vincristine has been mostly reported as a combinatorial agent with cyclophosphamide, cisplatin, bleomycin, methotrexate, and 5-FU in HNSCC [26-28]. For example, the combination of vincristine, bleomycin, and methotrexate produced a response rate of the primary tumor in 61\% [29]. As part of the CABO (cisplatin, methotrexate, bleomycin and vincristine) regimen, the overall response rate was $34 \%$ in a phase III trial of recurrent or metastatic HNSCC [30].

The role of B cells in solid tumors has also been under intense examination. B cells can exert their tumorigenic effects by secretion of paracrine factors that sustain chronic inflammation [31], deposition of immune complexes and $\mathrm{Fc} \gamma$ receptor-dependent activation of myeloid cells, and by enhancing $\mathrm{T}_{\mathrm{H}} 2$-type $\mathrm{CD}_{4}^{+} \mathrm{T}$ helper cells while repressing $\mathrm{CD}^{+} \mathrm{T}_{\mathrm{H}} 1$ cells which influence $\mathrm{CD} 8^{+}$ cytotoxic T cell activity [32]. As human SCCs of the vulva and head and neck exhibit hallmarks of B cell infiltration, it is postulated that rituximab, a chimeric monoclonal antibody against CD20 that leads to B cell depletion [33], could be considered in solid tumors [32]. Indeed, in a preclinical murine model of HPV16-related SCC, administration of rituximab to mice bearing preexisting SCCs improved response to platinum- and taxol-based chemotherapy, although it was ineffective as a single agent. This process was dependent on expression of an altered repertoire of chemokines expressed by macrophages, resulting in increased recruitment of cytotoxic $\mathrm{T}$ lymphocytes. A pilot clinical study in advanced colon cancer patients treated with rituximab reported encouraging tumor regressions [34]. Therefore it is possible that depletion of $\mathrm{B}$ cells with rituximab also played a role in the response of HNSCC to R-CHOP in this case. It should be noted that in addition to $\mathrm{B}$ cell depletion from rituximab, the treatment of lymphoma with R-CHOP possibly led to broad immunologic changes, restoring immune function in general.

The excellent response could also be attributed to the inherent treatment-sensitive biology of $\mathrm{HPV}^{+} \mathrm{SCC} . \mathrm{HPV}^{+}$ patients have better progression-free survival, lower locoregional failure rates, and improved 3-year overall survival in the setting of treatment with sequential chemoradiation and even after radiotherapy alone [35]. Therefore HPV positivity may confer a more favorable prognosis in a "platform-independent" manner. In a prospective trial of lowrisk $\mathrm{HPV}^{+}$patients (T1-3 N0-N2b), 3 cycles of induction chemotherapy with cisplatin, paclitaxel, and cetuximab achieved an excellent complete clinical response (cCR) rate of $70 \%$, which subsequently enabled them to be treated with a substantially lower dose of radiation (54Gy vs. 69 . 3Gy) [36]. In fact, the benefit of chemotherapy is unclear in this selected group of low-risk patients and efforts are underway to evaluate if chemotherapy can be omitted altogether ([35] and clinical trial NCT02254278).

In the present case, we would not have been able to observe the therapeutic effect of R-CHOP on SCC had we decided to treat SCC first with concurrent CRT. The main reason we prioritized treating lymphoma was the concern that the index retroperitoneal mass represented transformed lymphoma. However, this could not be ascertained without a tissue biopsy which was contraindicated due to the large size and vascularity of the mass. In addition, the high proliferation rate of the surrounding nodal disease, bulky disease, and relatively good prognosis of SCC all conspired for an upfront aggressive chemotherapy regimen like R-CHOP.

\section{Conclusions}

We report a case of synchronous retroperitoneal follicular lymphoma and $\mathrm{HPV}^{+}$BOT $\mathrm{HNSCC}$ in a 64 year-old female patient in which HNSCC had an excellent response to $\mathrm{R}-\mathrm{CHOP}$ chemotherapy before definitive chemoradiation therapy. Although there are published case reports of synchronous SCC of the aerodigestive tract and NHL [22-24, 37-48], this is the first to report a dramatic response of SCC to R-CHOP.This case highlights the exquisite sensitivity of HPV-related HNSCC, which should be taken into consideration in treatment prioritization in the setting of a concurrent diagnosis of a second cancer. The exact agent(s) responsible for the observed response is unclear but the immunomodulatory effect of rituximab and/or the cytotoxic effect of cyclophosphamide, doxorubicin and vincristine could each have played a role.

\section{Abbreviations \\ 5-FU: 5-fluorouracil; BOT: Base of tongue; CABO: Cisplatin, methotrexate, bleomycin and vincristine; CCR: Complete clinical response; CRT: Concurrent chemoradiation; CT: Computed tomography; EGFR: Epidermal growth factor receptor; HNSCC: Squamous cell carcinoma of the head and neck; HPV: Human papillomavirus; NSTEMI: non-ST-elevation myocardial infarction; OPC: Oropharyngeal cancer; PET/CT: Positron emission tomography/ computed tomography; R-CHOP: Rituximab, cyclophosphamide, doxorubicin, vincristine, and prednisone; RT: Radiation therapy; SCC: Squamous cell carcinoma; SPC: Second primary cancer}

Authors' contributions

APK and HK were directly involved in the care of the patient described in this report and were responsible for the study concept and design. Patient data were acquired and analyzed by TMM and SPR. SPR supervised analysis of the radiographic images. TMM and SPR drafted the manuscript. All authors read and approved the final manuscript. 


\section{Ethics approval and consent to participate}

The study was approved by the Johns Hopkins University Institutional Review Board, Baltimore, MD. The study was performed in accordance with the Declaration of Helsinki.

\section{Consent for publication}

Informed consent was obtained from the patient involved in the study.

\section{Competing interests}

The authors declare that they have no competing interests.

\section{Publisher's Note}

Springer Nature remains neutral with regard to jurisdictional claims in published maps and institutional affiliations.

\section{Author details}

${ }^{1}$ Department of Radiation Oncology and Molecular Radiation Sciences, The Johns Hopkins University School of Medicine, Baltimore, MD 21231, USA. 2Department of Oncology, The Johns Hopkins University School of Medicine, Baltimore, MD 21287, USA. ${ }^{3}$ The Russell H. Morgan Department of Radiology and Radiological Science, The Johns Hopkins University School of Medicine, Baltimore, MD 21287, USA

\section{Received: 14 November 2017 Accepted: 1 May 2018} Published online: 24 May 2018

\section{References}

1. Sanderson RJ, Ironside JA. Squamous cell carcinomas of the head and neck. BMJ. 2002;325:822-7.

2. Jain KS, Sikora AG, Baxi SS, Morris LG. Synchronous cancers in patients with head and neck cancer: risks in the era of human papillomavirus-associated oropharyngeal cancer. Cancer. 2013;119:1832-7.

3. Krishnatreya M, Rahman T, Kataki AC, Das A, Das AK, Lahkar K. Synchronous primary cancers of the head and neck region and upper aero digestive tract: defining high-risk patients. Indian J Cancer. 2013;50:322-6.

4. Levi F, Randimbison L, Te VC, La Vecchia C. Non-Hodgkin's lymphomas, chronic lymphocytic leukaemias and skin cancers. Br J Cancer. 1996;74:1847-50.

5. Jones SE, Griffith K, Dombrowski P. Gaines JA. Immunodeficiency in patients with non-Hodgkin lymphomas. Blood. 1977;49:335-44.

6. Brewer JD, Habermann TM, Shanafelt TD. Lymphoma-associated skin cancer: incidence, natural history, and clinical management. Int J Dermatol. 2014;53:267-74.

7. Brewer JD, Shanafelt TD, Khezri F, Sosa Seda IM, Zubair AS, Baum CL, Arpey CJ, Cerhan JR, Call TG, Roenigk RK, et al. Increased incidence and recurrence rates of nonmelanoma skin cancer in patients with non-Hodgkin Iymphoma: a Rochester epidemiology project population-based study in Minnesota. J Am Acad Dermatol. 2015;72:302-9.

8. Hartley BE, Searle AE, Breach NM, Rhys-Evans PH, Henk JM. Aggressive cutaneous squamous cell carcinoma of the head and neck in patients with chronic lymphocytic leukaemia. J Laryngol Otol. 1996;110:694-5.

9. Dasanu CA, Alexandrescu DT. Risk for second nonlymphoid neoplasms in chronic lymphocytic leukemia. MedGenMed. 2007;9:35.

10. Agnew KL, Ruchlemer R, Catovsky D, Matutes E, Bunker CB. Cutaneous findings in chronic lymphocytic leukaemia. Br J Dermatol. 2004;150:1129-35.

11. Drenou B, Le Friec G, Bernard M, Pangault C, Grosset JM, Lamy T, Fauchet R, Amiot L. Major histocompatibility complex abnormalities in non-Hodgkin lymphomas. Br J Haematol. 2002;119:417-24.

12. Laurent C, Charmpi K, Gravelle P, Tosolini M, Franchet C, Ysebaert L, Brousset P, Bidaut A, Ycart B, Fournie JJ. Several immune escape patterns in non-Hodgkin's lymphomas. Oncoimmunology. 2015;4:e1026530.

13. Upadhyay R, Hammerich L, Peng P, Brown B, Merad M, Brody JD. Lymphoma: immune evasion strategies. Cancers. 2015;7:736-62.

14. Menter T, Tzankov A. Mechanisms of immune evasion and immune modulation by lymphoma cells. Front Oncol. 2018;8:54

15. Dalla-Favera R. Molecular genetics of aggressive B-cell lymphoma. Hematol Oncol. 2017;35(Suppl 1):76-9.

16. Gillison ML, Chaturvedi AK, Anderson WF, Fakhry C. Epidemiology of human papillomavirus-positive head and neck squamous cell carcinoma. J Clin Oncol. 2015;33:3235-42.

17. Chaturvedi AK, Engels EA, Pfeiffer RM, Hernandez BY, Xiao W, Kim E, Jiang B, Goodman MT, Sibug-Saber M, Cozen W, et al. Human papillomavirus and rising oropharyngeal cancer incidence in the United States. J Clin Oncol. 2011:29:4294-301.

18. Intaraphet S, Farkas DK, Johannesdottir Schmidt SA, Cronin-Fenton D, Sogaard M. Human papillomavirus infection and lymphoma incidence using cervical conization as a surrogate marker: a Danish nationwide cohort study. Hematol Oncol. 2017:35:172-6.

19. Kumar B, Cipolla MJ, Old MO, Brown NV, Kang SY, Dziegielewski PT, Durmus K, Ozer E, Agrawal A, Carrau RL, et al. Surgical management of oropharyngeal squamous cell carcinoma: survival and functional outcomes. Head Neck. 2016;38(Suppl 1):E1794-802.

20. Ang KK, Harris J, Wheeler R, Weber R, Rosenthal DI, Nguyen-Tan PF, Westra WH, Chung $\mathrm{CH}$, Jordan RC, Lu C, et al. Human papillomavirus and survival of patients with oropharyngeal cancer. N Engl J Med. 2010;363:24-35.

21. Bonner JA, Harari PM, Giralt J, Azarnia N, Shin DM, Cohen RB, Jones CU, Sur R, Raben D, Jassem J, et al. Radiotherapy plus cetuximab for squamous-cell carcinoma of the head and neck. N Engl J Med. 2006;354:567-78.

22. Morita Y, Kimoto N, Ogawa H, Omata T, Morita N. Squamous cell carcinoma and malignant lymphoma as synchronous malignant Tumours in the oral cavity. Asian J Oral Maxillofac Surg. 2009:21:64-8

23. Fujii M, Shirai T, Asada K, Saito Y, Hirose M, Suda T. Synchronous diffuse large B-cell lymphoma and squamous cell lung carcinoma. Respirol Case Rep. 2014;2:33-5.

24. Oikonomou A, Astrinakis E, Kotsianidis I, Kaloutsi V, Didilis V, Tsatalas K, Prassopoulos P. Synchronous BALT lymphoma and squamous cell carcinoma of the lung: coincidence or linkage? Case Rep Oncol Med. 2013;2013:420393.

25. Carter SK. The chemotherapy of head and neck cancer. Semin Oncol. 1977; 4:413-24.

26. Al-Sarraf M. Chemotherapy strategies in squamous cell carcinoma of the head and neck. Crit Rev Oncol Hematol. 1984;1:323-55.

27. Richman SP, Livingston RB, Gutterman JU, Suen JY, Hersh EM Chemotherapy versus chemoimmunotherapy of head and neck cancer: report of a randomized study. Cancer Treat Rep. 1976;60:535-9.

28. Clavel M, Cognetti F, Dodion P, Wildiers J, Rosso R, Rossi A, Gignoux B, Van Rymenant M, Cortes-Funes H, Dalesio O, et al. Combination chemotherapy with methotrexate, bleomycin, and vincristine with or without cisplatin in advanced squamous cell carcinoma of the head and neck. Cancer. 1987:60:1173-7.

29. Figueroa-Valles NR, Marcial VA, Velez-Garcia E, Cintron J, Vallecillo LA. Multidrug chemotherapy (vincristine-bleomycin-methotrexate) followed by radiotherapy in inoperable carcinomas of the head and neck: a pilot study of the radiation therapy oncology group. Am J Clin Oncol. 1982;5:399-404.

30. Clavel M, Vermorken JB, Cognetti F, Cappelaere P, de Mulder PH, Schornagel $\mathrm{JH}$, Tueni EA, Verweij J, Wildiers J, Clerico M, et al. Randomized comparison of cisplatin, methotrexate, bleomycin and vincristine (CABO) versus cisplatin and 5 -fluorouracil (CF) versus cisplatin (C) in recurrent or metastatic squamous cell carcinoma of the head and neck. A phase III study of the EORTC head and neck Cancer cooperative group. Ann Oncol. 1994;5:521-6.

31. Pillai S, Mattoo H, Cariappa A. B cells and autoimmunity. Curr Opin Immunol. 2011;23:721-31.

32. Coussens LM, Zitvogel L, Palucka AK. Neutralizing tumor-promoting chronic inflammation: a magic bullet? Science. 2013;339:286-91.

33. Kessel A, Rosner I, Toubi E. Rituximab: beyond simple B cell depletion. Clin Rev Allergy Immunol. 2008;34:74-9.

34. Tan TT, Coussens LM. Humoral immunity, inflammation and cancer. Curr Opin Immunol. 2007;19:209-16.

35. O'Sullivan B, Huang SH, Siu LL, Waldron J, Zhao H, Perez-Ordonez B, Weinreb I, Kim J, Ringash J, Bayley A, et al. Deintensification candidate subgroups in human papillomavirus-related oropharyngeal cancer according to minimal risk of distant metastasis. J Clin Oncol. 2013;31:543-50.

36. Marur S, Li S, Cmelak AJ, Gillison ML, Zhao WJ, Ferris RL, Westra WH, Gilbert J, Bauman JE, Wagner LI, et al. E1308: phase II trial of induction chemotherapy followed by reduced-dose radiation and weekly Cetuximab in patients with HPV-associated Resectable squamous cell carcinoma of the oropharynx- ECOG-ACRIN Cancer research group. J Clin Oncol.

37. Kaur P, Khurana A, Chauhan AK, Singh G, Katari SP. Non-Hodgkin's lymphoma of thyroid synchronously with squamous cell carcinoma base of tongue: a rare coincidence and treatment strategy. Intl J Head Neck Surg. 2014;5:155-7.

38. Sun Y, Shi YF, Zhou LX, Chen KN, Li XH. Synchronous pulmonary squamous cell carcinoma and mantle cell lymphoma of the lymph node. Case Rep Gen. 2011;2011:945181.

39. Hadjileontis CG, Kostopoulos IS, Kaloutsi VD, Nikolaou AC, Kotoula VA, Papadimitriou CS. An extremely rare case of synchronous occurrence in the 
larynx of intravascular lymphoma and in situ squamous cell carcinoma. Leuk Lymphoma. 2003;44:1053-7.

40. Tezer MS, Tuncel U, Uzlugedik S, Uzun M, Kulacoglu S, Unal A. Coexistence of laryngeal squamous cell carcinoma and non-Hodgkin's lymphoma with nasopharyngeal involvement. J Laryngol Otol. 2006;120:e2.

41. Nigri PT, Khasgiwala CK. Unusual presentation of head and neck neoplasm. Laryngoscope. 1982;92:1245-6.

42. Shudo A, Takenobu T, Hirai Y, Yamamoto S, Taniike N, Usami Y. A case of synchronous squamous cell carcinoma of the mandibular gingiva and primary malignant lymphoma of the neck. Japanese J Oral Maxillofac Surg. 2017:63:45-50

43. Park JH, Lee JH, Lim Y, Lee YJ, Lee DY. Synchronous occurrence of primary cutaneous anaplastic large cell lymphoma and squamous cell carcinoma. Ann Dermatol. 2016;28:491-4.

44. Kader I, Leavers B, Shashinder S, Wylie B, Chi KK, Sundaresan P. Synchronous or metachronous lymphoma and metastatic cutaneous squamous cell carcinoma in the head and neck region: a diagnostic and management dilemma. J Laryngol Otol. 2016;130(Suppl 4):S45-9.

45. Watanabe N, Inohara H, Akahani S, Yamamoto Y, Moriwaki K, Kubo T. Synchronous squamous cell carcinoma and malignant lymphoma in the head and neck region. Auris Nasus Larynx. 2007;34:273-6.

46. Fonseca D, Musthyala B, Ahmed F, Murthy SS, Raju KV. A tale of synchronous lung carcinoma and diffuse large B-cell lymphoma of ileum: a rare combination. Lung India. 2015;32:398-401.

47. Heidemann LN, Johansen J, Larsen SR, Sorensen JA. Four synchronous cancers in a patient with tongue pain as the only symptom. BMJ Case Rep. 2016;2016. https://www.ncbinlm.nih.gov/pubmed/2715.

48. Raldow AC, Brown JG, Chau N, Davids MS, Margalit DN, Tishler RB, Ng A, Schoenfeld JD. Synchronous squamous cell carcinoma and diffuse large B-cell lymphoma of the head and neck: the odd couple. BJR Case Rep. 2016;2:1-4.

Ready to submit your research? Choose BMC and benefit from:

- fast, convenient online submission

- thorough peer review by experienced researchers in your field

- rapid publication on acceptance

- support for research data, including large and complex data types

- gold Open Access which fosters wider collaboration and increased citations

- maximum visibility for your research: over $100 \mathrm{M}$ website views per year 